\title{
Glucagon-like peptide-1 analogue liraglutide ameliorates atherogenesis via inhibiting advanced glycation end product-induced receptor for advanced glycosylation end product expression in apolipoprotein-E deficient mice
}

\author{
PEICHENG LI, ZHAOSHENG TANG, LIN WANG and BO FENG \\ Department of Endocrinology, Shanghai East Hospital, Tongji University School of Medicine, Shanghai 200000, P.R. China
}

Received July 6, 2016; Accepted May 3, 2017

DOI: $10.3892 / \mathrm{mmr} .2017 .6978$

\begin{abstract}
Glucagon-like peptide-1 (GLP-1) can protect arteriosclerotic lesions in apolipoprotein-E deficient ( $A p o E$ ${ }^{\prime}$ ) mice. Advanced glycation end products (AGEs)/receptor for advanced glycation end products (RAGE) interaction serves a key role in the development of diabetic vascular complications. The present study examined whether the GLP-1 analogue liraglutide can ameliorate atherogenesis via inhibiting AGEs-induced RAGE expression. Male $\mathrm{ApoE}^{-/-}$ mice (age, 10 weeks) were divided into control, GLP-1, AGEs and AGEs+GLP-1 group. All mice were fed a high-fat diet. The AGEs and AGEs+GLP-1 groups were treated with intraperitoneal injection of AGEs ( $30 \mathrm{mg} / \mathrm{kg} / \mathrm{day})$. The GLP-1 and AGEs+GLP-1 groups were treated with subcutaneous injections of liraglutide $(0.4 \mathrm{mg} / \mathrm{kg} / \mathrm{day})$. After 9 weeks, blood was drawn and the aortas were rapidly procured. The serum levels of AGEs, soluble RAGE (sRAGE), stromal cell-derived factor- $1 \alpha$ (SDF-1 $\alpha$ ), total cholesterol and triacylglycerol were measured. Atherosclerotic plaque area was determined by Sudan IV staining. The mRNA and protein expression levels of RAGE were determined using reverse transcriptionquantitative polymerase chain reaction and western blotting, respectively. The results demonstrated that AGEs treatment increased serum AGEs levels, increased the expression of RAGE in the aorta, and aggravated atherosclerotic lesions compared with the control. Liraglutide treatment reduced
\end{abstract}

Correspondence to: Professor Bo Feng, Department of Endocrinology, Shanghai East Hospital, Tongji University School of Medicine, 150 Jimo Road, Shanghai 200000, P.R. China

E-mail: fengbo@medmail.com.cn

Abbreviations: AGEs-BSA, advanced glycation end productsmodified bovine serum albumin; RAGE, receptor of advanced glycation end products; GLP-1, glucagon-like peptide-1

Key words: glucagon-like peptide-1, atherosclerosis, advanced glycosylation end products, receptor for advanced glycosylation end products, $A p o E^{-/-}$mice serum AGEs levels, reduced the expression of RAGE in aorta, and relieved atherosclerotic lesions compared with the control. In conclusion, these data suggested that liraglutide serves an anti-atherosclerotic effect via inhibiting AGEs-induced RAGE expression in $\mathrm{ApoE}^{-/}$mice. These findings provide novel evidence for the use of GLP-1-type agents for the treatment of diabetic vascular complications.

\section{Introduction}

Diabetes is a global health challenge. According to the recent report of Diabetes Atlas, 380 million people have diabetes, and the number is still increasing (1). Diabetic vascular complications are considered as the leading cause of morbidity and mortality in diabetic patients (2). In the course of treatment for diabetes, the delay of diabetic complications, such as macroangiopathy, is even more important than the control of serum glucose $(3,4)$.

Glucagon-like peptide-1 (GLP-1) and its analogues, including liraglutide, serve a key role in stimulation of insulin release and inhibition of glucagon release in a glucose-dependent manner, and maintain the glycemic homeostasis. Previous studies have revealed that GLP-1 can protect arteriosclerotic lesions by ameliorating hyperglycemia, decreasing blood pressure, reducing macrophage infiltration (5), and improving vascular inflammation (6) and endothelial dysfunction (7).

Advanced glycation end products (AGEs) are a diverse group of complex compounds which are formed via a chain of non-enzymatic chemical reactions (8). The formation and accumulation of AGEs progress under diabetic conditions. Accumulating evidence has suggested that receptor for (R) AGE serves a pivotal role in promoting inflammatory processes and endothelial activation, which accelerates atherosclerosis in patients with diabetes $(9,10)$. Binding of AGEs to RAGE activates multiple intracellular signaling pathways including $\mathrm{p} 21 \mathrm{ras}$, which recruits downstream targets such as mitogen-activated protein kinase, and activates nuclear factor $\kappa \mathrm{B}(\mathrm{NF}-\kappa \mathrm{B})$. The AGE-RAGE interaction augments inflammatory responses, and leads to vascular dysfunction and monocyte activation (9). Diabetes-associated atherosclerotic lesions exhibit increased accumulation of RAGE ligands and enhanced expression of RAGE $(11,12)$. Therefore, inhibition of AGE formation 
and blockage of RAGE may be a novel molecular target for protecting diabetic vascular complications. In our previous studies, it was demonstrated that atorvastatin can significantly downregulate the expression of RAGE in the aortas of diabetic Goto Kakiski rats, without an alteration in glucose levels (13). GLP-1 analogues can influence AGE levels via lowering blood glucose and subsequently altering the expression of RAGE. However, no research has been conducted on the direct effects of GLP-1 analogue on the formation and deposition of AGEs and the expression of RAGE in healthy animal models. The present study aimed to investigate whether GLP-1 analogue could decrease the AGE-induced increase in serum level of AGEs, and suppress the expression of RAGE in the aorta in an $A p o E^{-/-}$mouse model in euglycemia conditions. These results will further confirm the protective effects of GLP-1 analogue on arteriosclerotic lesions by targeting RAGE.

\section{Materials and methods}

Animals and treatment. Male C57BL/6 J ApoE $E^{-/-}$mice (age, 10 weeks; $n=40$ ) were purchased from Beijing Vital River Laboratory Animal Technology Co., Ltd. (Beijing, China) and were acclimated in their new environment for 2 weeks. Mice were housed in the animal facility of Shanghai University of Traditional Chinese Medicine (Shanghai, China) with free access to food and water and in a pathogen-free environment with a 12-h light/dark cycle. After the adjustment time, all the animals were fed a high-fat diet. Animals were randomly assigned to the control group $(n=10)$, GLP-1 group $(n=10)$, AGEs group $(n=10)$ and AGEs+GLP-1 group $(n=10)$. The GLP-1 and AGEs+GLP-1 groups received liraglutide (Novo Nordisk, Bagsværd, Denmark; $0.4 \mathrm{mg} / \mathrm{kg} /$ day) for 9 weeks by subcutaneous injection. The AGEs and AGEs+GLP-1 group received AGEs-modified bovine serum albumin (BSA; $30 \mathrm{mg} / \mathrm{kg} /$ day) for 9 weeks by intraperitoneal injection. Body weight, random blood glucose and individual food intake were monitored weekly. After 9 weeks, the mice were killed after $15 \mathrm{~h}$ of fasting, $\sim 1 \mathrm{ml}$ blood was drawn and the aorta from the aortic root to the iliac bifurcation was rapidly procured. Sudan IV staining requires a whole aorta, therefore, in each group 5 of the aortas were assessed by Sudan IV staining, and the other 5 were used for western blotting and reverse transcription-quantitative polymerase chain reaction (RT-qPCR). The present study was approved by the ethics committee of Tongji University School of Medicine (Shanghai, China).

Preparation of AGEs-BSA. AGEs-BSA was prepared in vitro as previously described (14). BSA (50 g/l; Sigma-Aldrich; Merck KGaA, Darmstadt, Germany), 500 mmol/l D-glucose (Sigma-Aldrich; Merck KGaA), $100 \mathrm{U} / \mathrm{ml}$ penicillin (Gibco; Thermo Fisher Scientific, Inc., Waltham, MA, USA) and $0.1 \mathrm{mg} / \mathrm{ml}$ streptomycin (Gibco; Thermo Fisher Scientific, Inc.) were dissolved in phosphate buffer $(0.2 \mathrm{M}, \mathrm{pH} 7.4)$, mixed and incubated overnight at room temperature. The mixture was sterilized by $0.22 \mu \mathrm{m}$ bacterial filter and then incubated at $37^{\circ} \mathrm{C}$ in the dark for 90 days, followed by extensive dialysis using $0.1 \mathrm{M}$ phosphate buffer for $24 \mathrm{~h}$ to remove unincorporated glucose. Fluorescence spectrophotometry (slit, $2.5 \mathrm{~nm}$; voltage $700 \mathrm{mv}$ ) with excitation and emission wavelengths of $370 \mathrm{~nm}$ and $440 \mathrm{~nm}$, respectively, AGEs-BSA was confirmed to be successfully prepared, which was subsequently made into lyophilized powder using a lyophilized powder machine.

Serum biochemical index measurement. The serum levels of AGEs (cat.no. MU30166), soluble (s)RAGE (cat. no. MU10877), stromal cell-derived factor (SDF)-1 $\alpha$ (cat. no. MU30235), total cholesterol (CHO; cat. no. MU30383) and triacylglycerol (TG; cat. no. MU30320) were measured using commercially available ELISA kits (Bio-Swamp Life Science Lab, Hubei, China), according to the manufacturer's protocols.

$R T-q P C R$. Total RNA in aorta tissue was obtained from frozen tissue (half of the aorta tissue) using TRIzol reagent (Invitrogen; Thermo Fisher Scientific, Inc.). Purified RNA was used as template for first-strand cDNA synthesis using a PrimeScript RT reagent kit (Takara Bio, Inc., Otsu, Japan). qPCR was performed with a SYBR Green PCR kit (Takara Bio, Inc.), using an ABI 7500 real-time PCR system, according to the manufacturer's instructions, with the following thermocycling conditions: 1 cycle at $95^{\circ} \mathrm{C}$ for $30 \mathrm{sec}$, then 40 cycles of $95^{\circ} \mathrm{C}$ for $5 \mathrm{sec}$ and $60^{\circ} \mathrm{C}$ for $34 \mathrm{sec}$. Gene expressions were analyzed using the comparative $\mathrm{Cq}$ method (15) and normalized to GADPH. Primers (Sangon Biotech, Co., Ltd., Shanghai, China) were as follows: Forward, 5'-GAA-GGC-TCT-GTG-GGT-GAG-TC-3' and reverse, 5'-ATT-CAG-CTC-TGC-ACG-TTC-CT-3' for RAGE; and forward, 5'-CCT-GA-CCA-CCA-ACT-GCT-TAG-C-3' and reverse, 5'-CCA-GTG-AGC-TTC-CCG-TCT-AGC-3' for GAPDH.

Western blot analysis. Total proteins of the other half of the aorta tissue were initially extracted by centrifugation $(16,000 \mathrm{x} \mathrm{g}$ for $5 \mathrm{~min}$ at $4^{\circ} \mathrm{C}$ ) in radioimmunoprecipitation assay lysis buffer (Beyotime Institute of Biotechnology, Haimen, China). Protein concentrations were determined using an Enhanced Bicinchoninic Acid Protein Assay kit according to the manufacturer's instructions (Beyotime Institute of Biotechnology). Equal amounts $(20 \mu \mathrm{g})$ of protein samples separated by 10 or $12 \%$ SDS-PAGE and then transferred onto a polyvinylidene difluoride membrane. The non-specific proteins were blocked with 5\% non-fat dried milk for $1 \mathrm{~h}$. The membranes were incubated with anti-RAGE (cat. no. ab37647; Abcam, Cambridge, MA, USA; 1:500) and anti-GAPDH (cat. no. BM3876; Boster Biological Technology, Pleasanton, CA, USA; 1:2,000) primary antibodies overnight at $4^{\circ} \mathrm{C}$, followed by incubation with horseradish peroxidase (HRP)-conjugated $\mathrm{IgG}$ secondary antibodies (cat. nos. 111-055-003 and 115-035-003; Jackson ImmunoResearch Laboratories, Inc., West Grove, PA, USA; 1:2,000) for $1 \mathrm{~h}$ at room temperature. HRP-conjugated secondary antibodies were used in conjunction with an enhanced chemiluminescence detection system. Protein expression was analyzed using Gel-Pro analyzer 4 software (Media Cybernetics, Inc., Rockville, MD, USA) and normalized to that of GAPDH.

Quantification of atherosclerotic lesions. The atherosclerotic lesions were assessed by Sudan IV staining as previously described (16). The entire aorta was dissected from the proximal ascending aorta to the bifurcation of the iliac artery, fixed with $10 \%$ formalin for $36 \mathrm{~h}$, and then stained with Sudan IV for $10 \mathrm{~min}$, differentiated in $70 \%$ alcohol for $15 \mathrm{~min}$, and 


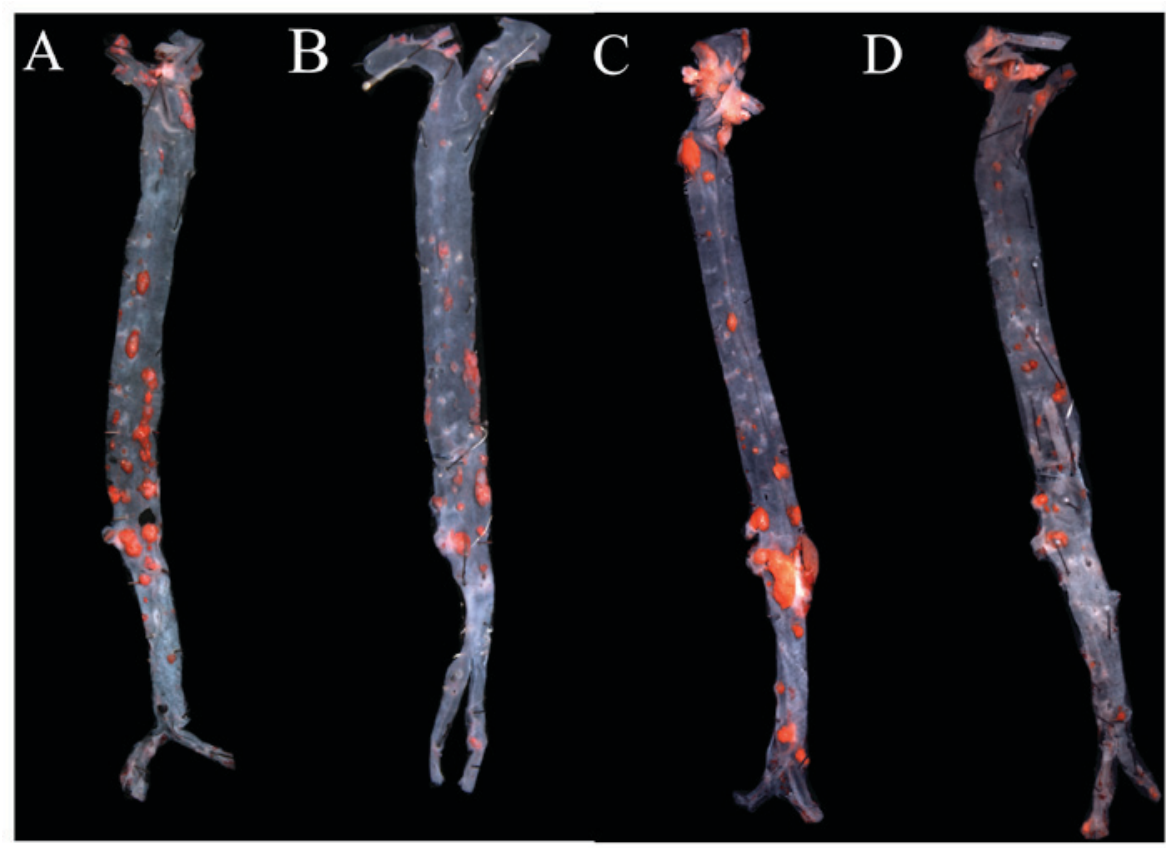

Figure 1. Atherosclerotic lesion progression in apolipoprotein-E deficient mice were assessed by Sudan IV staining (magnification, x50). (A) control group; (B) GLP-1 group; (C) AGEs group, (D) AGEs+GLP-1 group. AGEs, advanced glycation end products; GLP-1, glucagon-like peptide-1.

washed in water for $30 \mathrm{~min}$. The adventitial fat was removed and the aorta was opened longitudinally and pinned flat onto a black paraffin board using a dissecting microscope. The aorta was imaged using a charged couple device camera. The images were merged into one image using Adobe Photoshop Version 7.0 (Adobe Systems, Inc., San Jose, CA, USA). Total aortic and lesion areas were calculated using Image-Pro Plus 6.0 (National Institutes of Health, Bethesda, MA, USA). The results were reported as a percentage of the total aortic area that contained lesions.

Statistical analysis. Data are presented as the mean \pm standard deviation. Data were analyzed by one-way analysis of variance followed by a Fisher's least significant difference post hoc test using SPSS version 19.0 (IBM Corp., Armonk, NY,USA). P<0.05 was considered to indicate a statistically significant difference.

\section{Results}

Animal data and metabolic profile. Male mice (10 weeks old) matched for baseline body weight were fed with a high-fat diet. After a 9-week intervention, the body weight of $A p o E^{-/-}$mice in the GLP-1 group reduced compared with the control group $(\mathrm{P}<0.01)$, the food intake and random plasma glucose were reduced in GLP-1 treated groups compared with non-treated groups (all $\mathrm{P}<0.01$ ). Serum AGEs and sRAGE increased in the AGEs group compared with the control group (all $\mathrm{P}<0.01$ ), and serum AGEs and sRAGE were reduced in GLP-1 treated groups compared with non-treated groups, (all $\mathrm{P}<0.01$ ). SDF-1 $\alpha$ levels were increased in both AGEs and GLP-1 group compared with the control group (all $\mathrm{P}<0.05$ ), and SDF-1 $\alpha$ levels were increased in the AGEs+GLP-1 group compared with the AGEs group $(\mathrm{P}<0.05)$. There were no significant differences in serum TG and CHO levels between the four groups (Table I).

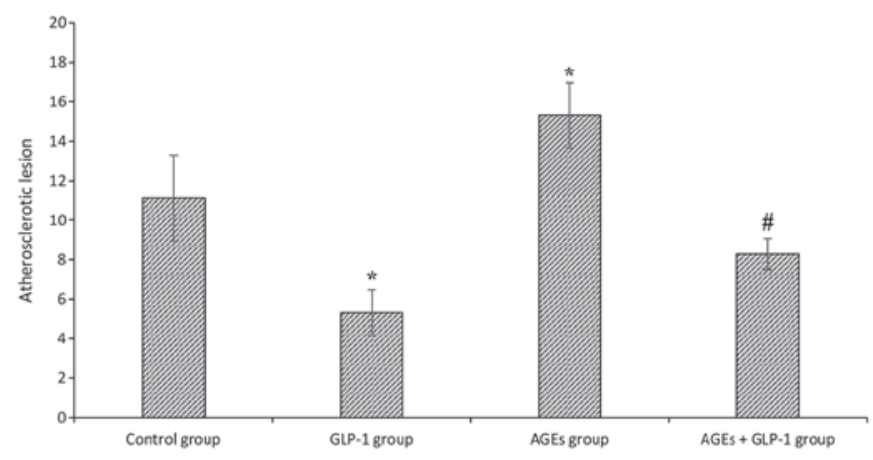

Figure 2. Atherosclerotic lesion progression in apolipoprotein-E deficient mice was assessed by Sudan IV staining. Data are expressed as the mean \pm standard deviation ( $\mathrm{n}=5 /$ group). ${ }^{*} \mathrm{P}<0.01$ vs. control group; ${ }^{\sharp} \mathrm{P}<0.01 \mathrm{vs}$. AGEs group. AGEs, advanced glycation end products; GLP-1, glucagon-like peptide-1.

AGEs aggravate atherosclerotic lesions, and GLP-1 treatment relieves it. To investigate the effect of AGEs on atherogenesis, ApoE $^{-/}$mice were treated with intraperitoneal injections of AGEs for 9 weeks, and then total plaque area in the entire aorta were assessed by Sudan IV staining. The aortic lesion size increased in AGEs groups compared with the control group $(\mathrm{P}<0.01)$. Additionally, aortic lesion size decreased in GLP-1 treated groups compared with non-treated groups (all $\mathrm{P}<0.01$; Figs. 1 and 2).

AGEs increase the expression of RAGE in aorta tissues, and GLP-1 treatment reduces it. To further analyze the mechanisms mediating aggravation in the atherosclerotic lesions in $\mathrm{ApoE}^{-/-}$mice, RAGE expression was measured in aorta tissues. In the AGEs groups, RAGEs protein and mRNA expression levels were increased compared with the control group (all $\mathrm{P}<0.01)$. GLP-1 treatment reduced RAGEs protein and mRNA 
Table I. Characteristics and laboratory data of apolipoprotein-E deficient mice treated for 9 weeks with a high-fat diet.

\begin{tabular}{lcccc}
\hline & Control group & GLP-1 group & AGEs group & AGEs+GLP-1 group \\
\hline Body weight $(\mathrm{g})$ & $31.2 \pm 1.6$ & $29.0 \pm 0.8^{\mathrm{a}}$ & $29.8 \pm 1.0$ & $29.4 \pm 1.9$ \\
Food intake (g/day) & $4.06 \pm 0.21$ & $2.96 \pm 0.36^{\mathrm{a}}$ & $3.72 \pm 0.41$ & $2.63 \pm 0.4^{\mathrm{b}}$ \\
Glucose $(\mathrm{mmol} / \mathrm{l})$ & $7.39 \pm 0.48$ & $6.66 \pm 0.37^{\mathrm{a}}$ & $7.39 \pm 0.45$ & $6.34 \pm 0.40^{\mathrm{b}}$ \\
AGEs $(\mathrm{pg} / \mathrm{ml})$ & $915.3 \pm 173.1$ & $589.4 \pm 66.4^{\mathrm{a}}$ & $2198.25 \pm 478.7^{\mathrm{a}}$ & $1217.1 \pm 199.0^{\mathrm{b}}$ \\
sRAGE $(\mathrm{pg} / \mathrm{ml})$ & $428.3 \pm 41.9$ & $340.5 \pm 65.3^{\mathrm{a}}$ & $617.0 \pm 123.0^{\mathrm{a}}$ & $389.6 \pm 83.3^{\mathrm{b}}$ \\
SDF-1 $\alpha(\mathrm{ng} / \mathrm{ml})$ & $6.14 \pm 1.01$ & $7.87 \pm 0.74^{\mathrm{a}}$ & $7.95 \pm 1.01^{\mathrm{a}}$ & $9.95 \pm 2.07^{\mathrm{b}}$ \\
TG $(\mathrm{mmol} / \mathrm{l})$ & $2.57 \pm 0.35$ & $2.99 \pm 0.41$ & $2.85 \pm 0.46$ & $2.96 \pm 0.32$ \\
CHO (mmol/l) & $13.3 \pm 2.2$ & $13.5 \pm 2.4$ & $13.6 \pm 1.9$ & $14.1 \pm 2.7$
\end{tabular}

Data are presented as the mean \pm standard deviation ( $\mathrm{n}=10 /$ group). ${ }^{\mathrm{a}} \mathrm{P}<0.01 \mathrm{vs}$. control group; ${ }^{\mathrm{b}} \mathrm{P}<0.01 \mathrm{vs}$. AGEs group. AGEs, advanced glycation end products; GLP-1, glucagon-like peptide-1; sRAGE, soluble receptor of advanced glycation end products; SDF-1 $\alpha$, stromal cell-derived factor- $1 \alpha$; $\mathrm{CHO}$, total cholesterol; TG, triacylglycerol.

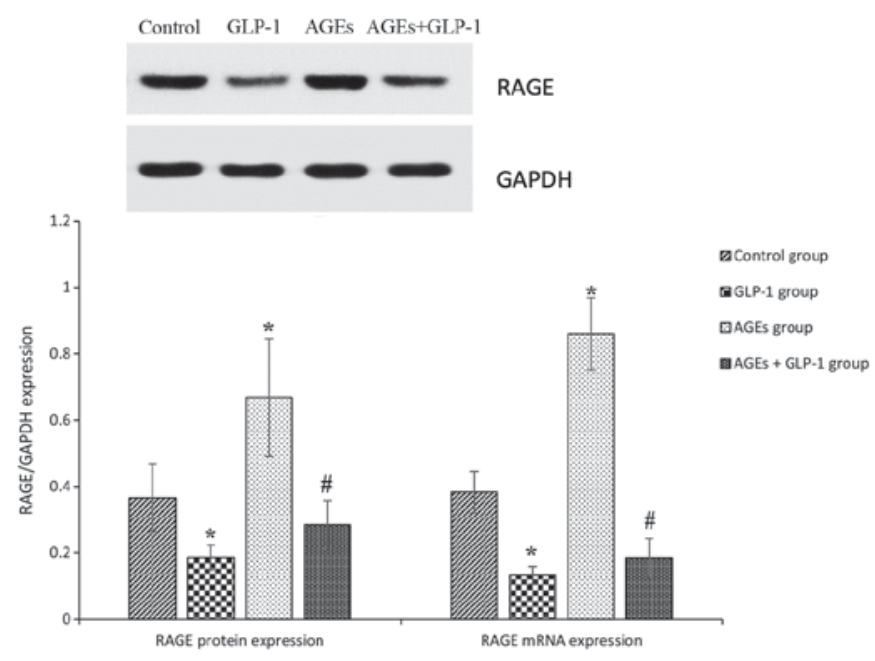

Figure 3. RAGE protein and mRNA expression levels in the aorta of apolipoprotein-E deficient mice. Data are expressed as the mean \pm standard deviation ( $\mathrm{n}=5$ /group). ${ }^{*} \mathrm{P}<0.01$ vs. control group; ${ }^{\text {P }} \mathrm{P}<0.01$ vs. AGEs group. AGEs, advanced glycation end products; GLP-1, glucagon-like peptide-1; RAGE, receptor of advanced glycation end products.

expression levels compared with the control and AGEs groups (all $\mathrm{P}<0.01$; Fig. 3).

\section{Discussion}

Previous studies have reported that GLP-1 reduces the development of atherosclerosis in $\mathrm{ApoE}^{-/-}$mice fed a highfat diet (17). However, the mechanism by which GLP-1 suppresses the development of atherosclerosis remains to be fully elucidated. The majority of studies have demonstrated that GLP-1 reduces vascular inflammation via suppression of pro-inflammatory activation of monocytes/macrophages (18). AGEs serve a pivotal role for the initiation and development of atherogenesis in type II diabetes mellitus (2-DM) via activing RAGE. Therefore, the present study examined whether GLP-1 can protect arteriosclerotic lesions via inhibiting AGEsinduced RAGE expression. The present results demonstrated that AGEs aggravate atherosclerotic lesions via increasing the expression of RAGE in aorta tissues, and liraglutide relieved it via downregulating the expression of RAGE in aorta tissues.

The present study subjected $A p o E^{-/-}$mice to a high-fat diet for 9 weeks to facilitate the development of atherosclerotic lesions at 12 weeks. Liraglutide reduced food intake and slowed the growth of body weight. Liraglutide has previously demonstrated pleiotropic effects on food intake, body weight, fat mass loss and energy expenditure (19), consistent with the results of the present study.

The present study revealed that intraperitoneal injection of AGEs significantly increased serum AGEs, which upregulated aortic RAGE expression and aggravated atherosclerotic lesions in $\mathrm{ApoE}^{-/-}$mice. AGEs are formed by the maillard process, a non-enzymatic reaction between reducing sugars and the amino groups of proteins, lipids and nucleic acids that contributes to the aging of macromolecules (20). In hyperglycemic and/or oxidative stress conditions, this process begins with the conversion of reversible Schiff base adducts to more stable, covalently-bound Amadori rearrangement products (21). Over the course of days to weeks, these Amadori products undergo further rearrangement reactions to form irreversibly-crosslinked moieties, termed AGEs (22). RAGE, one of the most important binding proteins of AGEs, is a signal-transducing receptor on the cell surface, and is upregulated by AGEs (23). Increasing evidence has demonstrated that activation of RAGE induced by AGEs elicits oxidative stress generation (24) and activation of NF- $\mathrm{B}$ (21). The AGEs-RAGE-induced oxidative stress generation further potentiates the formation and accumulation of AGEs and subsequent RAGE overexpression. Therefore, these positive feedback mechanisms may form a vicious cycle, and cause atherosclerosis in diabetes.

The present study demonstrated that liraglutide treatment decreased serum AGEs and the RAGE expression in the aorta, relieving atherosclerotic lesions in $\mathrm{ApoE}^{-/-}$mice. GLP-1 is one of the incretins, a gut hormone secreted from L cells in the intestine in response to food intake (25). GLP-1 suppress oxidative stress generation induced by AGEs-RAGE (26), then blocks the positive feedback loops between the AGEs-RAGE axis. GLP-1 receptor (GLP-1R) is expressed in vascular endothelial cells, and GLP-1R small interfering RNAs decrease 
RAGE mRNA expression levels. It has been demonstrated that GLP-1R activation may attenuate the abnormal expression of RAGE via the suppression of NF- $\mathrm{NB}$ (27).

Liraglutide decreased plasma glucose levels in the GLP-1 group compared with the control group, causing a decrease of serum AGEs. In the AGEs+GLP-1 group, serum AGEs were significantly decreased compared with AGEs group, without significant decrease of plasma glucose. Therefore, it was hypothesized that liraglutide has direct effects on metabolizing serum AGEs, and subsequently decreases RAGE expression in the aorta, relieving atherosclerotic lesions. However, the underlying mechanisms remain unclear. Perhaps these effects of liraglutide are associated with the activation of GLP-1R.

RAGE has a C-truncated secreted isoform, termed sRAGE. In contrast to cell surface RAGE, sRAGE blocks cell surface RAGE-ligand blinding and subsequent signaling by acting as a decoy (28). Previous studies have reported serum sRAGE levels as an important novel biomarker in patients with 2-DM (29) and in nondiabetic subjects with coronary artery disease (30). In the present study, liraglutide decreased serum sRAGE levels, which may be another reason for the decreased expression of RAGE in the aorta.

In the present study, serum SDF-1 $\alpha$ levels increased in $A p o E^{-/-}$mice treated with AGEs and/or liraglutide. SDF-1 is a small peptide chemokine that regulates many essential biological processes, including stem cell motility, cardiac and neuronal development, neovascularization, and tissue repair and regeneration (31). SDF-1 is produced in reactive stromal tissue in response to injuries, where it is believed to recruit bone marrow-drived somatic stem cells involved in tissue repair (32). A previous study suggested that GLP-1 could enhance the restorability of SDF-1 to beta cells (33). The results of the present study indicated that the increase of serum SDF-1 is a protective factor for arteriosclerotic lesion.

In conclusion, the results of the present study demonstrated that GLP-1 can protect arteriosclerotic lesions in $A p o E^{-1}$ mice. Additionally, the beneficial effects of GLP-1 involved reducing diet and losing weight. These observations indicated that GLP-1 has protective actions against atherosclerosis via inhibiting AGEs-induced RAGE expression. As the prevention and treatment of diabetic vascular complications remains an important and challenging issue, liraglutide, an effective medicine for diabetes, may provide attractive therapeutic options for atherosclerosis and associated diseases.

\section{Acknowledgements}

The present study was supported by Shanghai Pudong New District [grant no. 2011CB504006 (1)]. The authors would like to thank Professor Yuzhen Zhang (Shanghai East Hospital) for providing the method for Sudan IV staining of the entire aorta, and Professor Zhanyu Guo (School of Life Sciences and Technology, Tongji University) for the preparation of AGEs-BSA.

\section{References}

1. Whiting DR, Guariguata L, Weil C and Shaw J: IDF diabetes atlas: Global estimates of the prevalence of diabetes for 2011 and 2030. Diabetes Res Clin Pract 94: 311-321, 2011.
2. Haffner SM, Lehto S, Rönnemaa T, Pyörälä K and Laakso M: Mortality from coronary heart disease in subjects with type 2 diabetes and in nondiabetic subjects with and without prior myocardial infarction. N Engl J Med 339: 229-234, 1998.

3. Fowler MJ: Microvascular and Macrovascular Complications of Diabetes. Clinical Diabetes 26: 77-82, 2008.

4. Scheen AJ and Paquot N: Blood glucose control and prevention of microangiopathy and macroangiopathy in type 2 diabetes. Rev Med Liege 58: 265-270, 2003.

5. Wang Y, Parlevliet ET, Geerling JJ, van der Tuin SJ, Zhang H, Bieghs V, Jawad AH, Shiri-Sverdlov R, Bot I, de Jager SC, et al: Exendin-4 decreases liver inflammation and atherosclerosis development simultaneously by reducing macrophage infiltration. Br J Pharmacol 171: 723-734, 2014.

6. Dozier KC, Cureton EL, Kwan RO, Curran B, Sadjadi J and Victorino GP: Glucagon-like peptide-1 protects mesenteric endothelium from injury during inflammation. Peptides 30: 1735-1741, 2009.

7. Kim Chung le T, Hosaka T, Yoshida M, Harada N, Sakaue H, Sakai T and Nakaya Y: Exendin-4, a GLP-1 receptor agonist, directly induces adiponectin expression through protein kinase A pathway and prevents inflammatory adipokine expression. Biochem Biophys Res Commun 390: 613-618, 2009.

8. Yamagishi S: Role of advanced glycation end products (AGEs) and receptor for AGEs (RAGE) in vascular damage in diabetes. Exp Gerontol 46: 217-224, 2011.

9. Huttunen HJ, Fages C and Rauvala H: Receptor for advanced glycation end products (RAGE)-mediated neurite outgrowth and activation of NF-kappaB require the cytoplasmic domain of the receptor but different downstream signaling pathways. J Biol Chem 274: 19919-19924, 1999.

10. Bierhaus A, Schiekofer S, Schwaninger M, Andrassy M, Humpert PM, Chen J, Hong M, Luther T, Henle T, Klöting I, et al: Diabetes-associated sustained activation of the transcription factor nuclear factor-kappaB. Diabetes 50: 2792-2808, 2001.

11. Cipollone F, Iezzi A, Fazia M, Zucchelli M, Pini B, Cuccurullo C, De Cesare D, De Blasis G, Muraro R, Bei R, et al: The receptor RAGE as a progression factor amplifying arachidonate-dependent inflammatory and proteolytic response in human atherosclerotic plaques: Role of glycemic control. Circulation 108: 1070-1077, 2003.

12. Park L, Raman KG, Lee KJ, Lu Y, Ferran LJ Jr, Chow WS, Stern D and Schmidt AM: Suppression of accelerated diabetic atherosclerosis by the soluble receptor for advanced glycation endproducts. Nat Med 4: 1025-1031, 1998.

13. Feng B, Xu L, Wang H, Yan X, Xue J, Liu F and Hu JF: Atorvastatin exerts its anti-atherosclerotic effects by targeting the receptor for advanced glycation end products. Biochim Biophys Acta 1812: 1130-1137, 2011.

14. Vlassara H, Striker LJ, Teichberg S, Fuh H, Li YM and Steffes M: Advanced glycation end products induce glomerular sclerosis and albuminuria in normal rats. Proc Natl Acad Sci USA 91: 11704-11708, 1994.

15. Livak KJ and Schmittgen TD: Analysis of relative gene expression data using real-time quantitative PCR and the 2(-Delta Delta C(T)) method. Methods 25: 402-408, 2001.

16. Yagyu H, Ishibashi S, Chen Z, Osuga J, Okazaki M, Perrey S, Kitamine T, Shimada M, Ohashi K, Harada K, et al: Overexpressed lipoprotein lipase protects against atherosclerosis in apolipoprotein E knockout mice. J Lipid Res 40: 1677-1685, 1999.

17. Chrysant SG and Chrysant GS: Clinical implications of cardiovascular preventing pleiotropic effects of dipeptidyl peptidase-4 inhibitors. Am J Cardiol 109: 1681-1685, 2012.

18. Arakawa M, Mita T, Azuma K, Ebato C, Goto H, Nomiyama T, Fujitani Y, Hirose T, Kawamori R and Watada H: Inhibition of monocyte adhesion to endothelial cells and attenuation of atherosclerotic lesion by a glucagon-like peptide-1 receptor agonist, exendin-4. Diabetes 59: 1030-1037, 2010.

19. Knudsen LB: Liraglutide: The therapeutic promise from animal models. Int J Clin Pract Suppl: 4-11, 2010.

20. Vlassara $H$ and Palace MR: Diabetes and advanced glycation endproducts. J Intern Med 251: 87-101, 2002.

21. Fukami K, Yamagishi S and Okuda S: Role of AGEs-RAGE system in cardiovascular disease. Curr Pharm Des 20: 23952402,2014

22. Yamagishi S, Fukami K and Matsui T: Crosstalk between advanced glycation end products (AGEs)-receptor RAGE axis and dipeptidyl peptidase-4-incretin system in diabetic vascular complications. Cardiovasc Diabetol 14: 2, 2015. 
23. Sourris KC and Forbes JM: Interactions between advanced glycation end-products (AGE) and their receptors in the development and progression of diabetic nephropathy-are these receptors valid therapeutic targets. Curr Drug Targets 10: 42-50, 2009.

24. Daffu G, del Pozo CH, O'Shea KM, Ananthakrishnan R, Ramasamy R and Schmidt AM: Radical roles for RAGE in the pathogenesis of oxidative stress in cardiovascular diseases and beyond. Int J Mol Sci 14: 19891-19910, 2013.

25. Kim W and Egan JM: The role of incretins in glucose homeostasis and diabetes treatment. Pharmacol Rev 60: 470-512, 2008.

26. Ishibashi Y, Matsui T, Takeuchi M and Yamagishi S: Glucagonlike peptide-1 (GLP-1) inhibits advanced glycation end product (AGE)-induced up-regulation of VCAM-1 mRNA levels in endothelial cells by suppressing AGE receptor (RAGE) expression. Biochem Biophys Res Commun 391: 1405-1408, 2010.

27. Chen S, Yin L, Xu Z, An FM, Liu AR, Wang Y, Yao WB and Gao XD: Inhibiting receptor for advanced glycation end product (AGE) and oxidative stress involved in the protective effect mediated by glucagon-like peptide-1 receptor on AGE induced neuronal apoptosis. Neurosci Lett 612: 193-198, 2016.

28. Hudson BI, Harja E, Moser B and Schmidt AM: Soluble levels of receptor for advanced glycation endproducts (sRAGE) and coronary artery disease: The next C-reactive protein? Arterioscler Thromb Vasc Biol 25: 879-882, 2005.
29. Basta G, Sironi AM, Lazzerini G, Del Turco S, Buzzigoli E, Casolaro A, Natali A, Ferrannini E and Gastaldelli A: Circulating soluble receptor for advanced glycation end products is inversely associated with glycemic control and S100A12 protein. J Clin Endocrinol Metab 91: 4628-4634, 2006.

30. Falcone C, Emanuele E, D'Angelo A, Buzzi MP, Belvito C, Cuccia $\mathrm{M}$ and Geroldi D: Plasma levels of soluble receptor for advanced glycation end products and coronary artery disease in nondiabetic men. Arterioscler Thromb Vasc Biol 25: 1032-1037, 2005.

31. Ratajczak MZ, Zuba-Surma E, Kucia M, Reca R, Wojakowski W and Ratajczak J: The pleiotropic effects of the SDF-1-CXCR4 axis in organogenesis, regeneration and tumorigenesis. Leukemia 20: 1915-1924, 2006

32. Kucia M, Reca R, Jala VR, Dawn B, Ratajczak J and Ratajczak MZ: Bone marrow as a home of heterogenous populations of nonhematopoietic stem cells. Leukemia 19: 1118-1127, 2005.

33. Liu Z, Stanojevic V, Avadhani S, Yano T and Habener JF: Stromal cell-derived factor-1 (SDF-1)/chemokine (C-X-C motif) receptor 4 (CXCR4) axis activation induces intra-islet glucagon-like peptide-1 (GLP-1) production and enhances beta cell survival. Diabetologia 54: 2067-2076, 2011. 